\title{
The Relationship between Economy and the Development of New Energy
}

\author{
Tianyi Qu ${ }^{1, a}$ and Xiaofang Cao ${ }^{1, b}$ \\ ${ }^{1}$ School of Management,XuZhou institute of Technology, Xuzhou, Jiangsu, China 221008 \\ ajdbh2001@163.com bxfxzit@163.com
}

Keywords: New energy development; Economy; Influence; Strategy; Environmental issues

\begin{abstract}
In order to change the situation of the worse circumstance and energy shortage, how to develop new energy comes to be an issue related not only to China but also the whole world. Development of energy contributes closely to the economy growth. From the perspective of environmental protection, developing new energy sustainably ought to be regarded as the direction and criterion of optimizing energy structure as well as promoting sustainable economic development. Simultaneously, the cost of industrial production and civil life is reduced due to its development to some extent.
\end{abstract}

\section{Introduction}

Suffering growingly serious shortage with the prosperous economy, conventional energy leads to the gradually deteriorated circumstance problem such as greenhouse effect and acid rain. Advancement in technology makes it possible to exploit the new energy. With good effect obtained, new energy, such as nuclear energy, wind energy, solar energy, tidal energy, is introduced in the industrial production. Advanced technology and enlarged application field of them can optimize the industrial structure effectively and develop economic sustainably.

\section{Summary of New Energy}

Defined as renewable resource different from traditional non-renewable fossil fuels generally, new energy, from wind, solar, tide, and nuclear, is always exploited with modern technology. Exhaust, such as $\mathrm{CO} 2$ and $\mathrm{SO} 2$, from traditional source like coal and petroleum will pollute the air in the process of utilization. Non-renewable energy resource ought to be greatly responsible for the global energy crisis recent years. Renewable and inexhaustible, new energy will cause no environmental destruction conversely. It is a main way to alleviate energy shortage crisis that new energy ought to be exploited faster and gradually substitute the position of conventional energy resources. Global development of wind and solar energy is shown in Fig. 1 and Fig. 2 and their grid-connected models are illustrated respectively in Fig. 3 and Fig. 4.

\section{Development Status of New Energy Power Generation in China}

Currently, excluding common fossil fuels, nuclear power and large and hydro power, new energy is generally defined as primary energy from solar, wind, hydro, biomass, subterranean heat and ocean and secondary energy such as fuel cell and hydro genic energy. Recyclable, clean, abundant and widespread, the energy is the most promising substitutes and will be the cornerstone of the energy world in future.

With the great improvement of economy and living standard in China, environmental and energy resources problems, on the contrary, are increasingly deteriorating. Under this circumstance, our country accelerates the exploitation of new energy and augments economic investment accordingly. According to the status of our country, wind power technology is much more refined than others but is easily influenced by season and topography. Efficiency, technology of application and total power generation are greatly improved due to much more research from relevant technicians recent years. Exploitation of solar energy is also advanced and the photovoltaic cell is a chief form. With the utilization efficiency of solar cells increasing, solar power generation technology is becoming growingly mature. Consequently, the share of photovoltaic cells in China's new energy market is 
much higher than that of others. However, for geothermal and biomass energy, there is still a wide gap between China and other developed countries. Production costs, for enterprises, reduce due to exploitation of new energy promoting social progress. In some seriously-polluted area, the clear sky reappears for using clean energy source which contributes greatly to healthy economic growth in China. The distinct facts can't be ignored, including the radical investment strategies, backward industrial chains, under-developed technology and the poor implementation of government support policies. All the issues mentioned above make new energy develop abnormally and lag behind in core technology. In addition, with new energy entering international market difficultly for trade protectionism, healthy development comes to be gradually hard. This situation has to be changed for our country if we intend to further develop new energy.

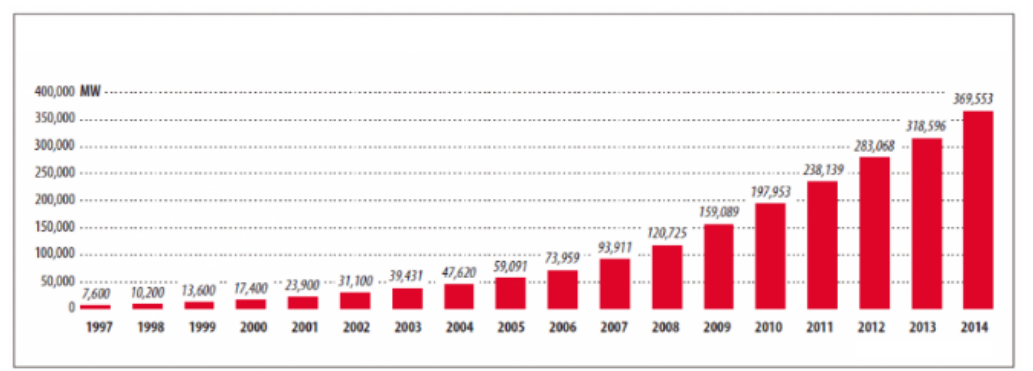

Figure.1 Development situation of global wind power installed capacity

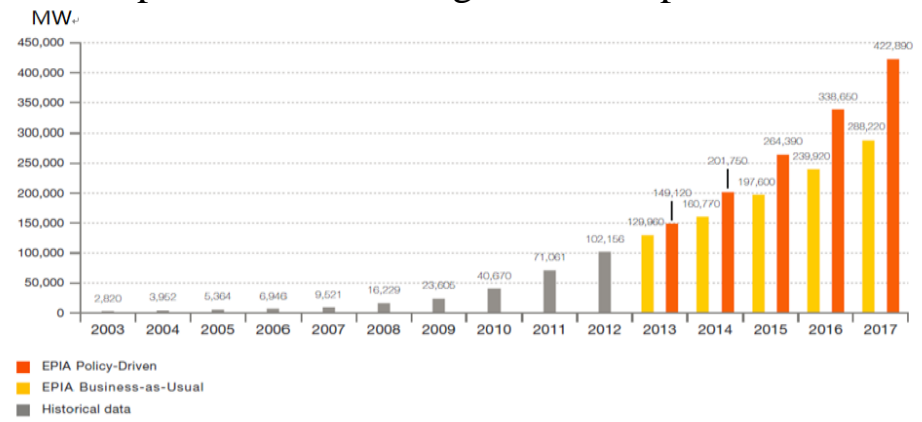

Figure.2 Development situation of global solar power installed capacity
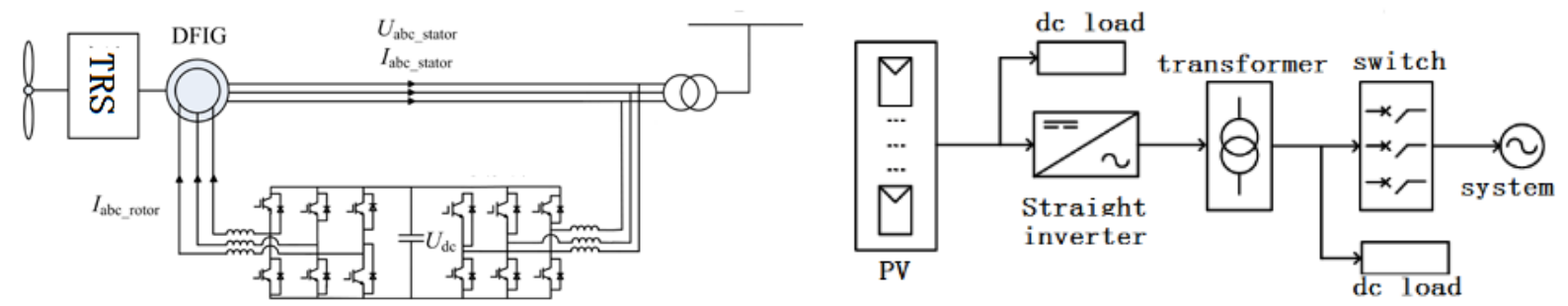

Figure.3 Grid-connected model of wind power Figure.4 Grid-connected model of solar power

\section{Trend and Prospect of New Energy Generation in China}

Having stepped into the stage of steady growth, wind power industry, in general, will not fluctuate greatly in its policy. It is expected that the total wind power capacity of China will reach 116 million $\mathrm{kW}$ hopefully. According to the layout of wind power installation, it can be concluded that wind power growth will further accelerate in the mid-eastern China but slow down in Three North Region with regional consumptive difficulties and the price adjustment in three kinds areas.

Currently, National Development and Reform Commission has issued grid-connected price of offshore wind power. National Energy Administration has released offshore wind power development and construction scheme that total installed capacity will reach 10.53 million $\mathrm{kW}$. In addition, the projects are mainly related to 8 coastal provinces among which offshore power generation from Jiangsu, Fujian, Guangdong and Hebei will reach more than 1 million kW. The development of offshore wind power is expected to further accelerate during the 13th Five-Year Plan period. 
With the decline in the price of PV modules, photovoltaic plant is expected to further reduce the levelized cost of energy which is less than 0.8 yuan / $(\mathrm{kW} \cdot \mathrm{h})$ now. Profits can be guaranteed because photovoltaic plants centrally connect to gird which monopolizes all the generation. Therefore, it can be inferred that the quantity of centralized photovoltaic power plant would be more than ever before.

With the implementation of photovoltaic support policies carried out, issues like difficult financing, high development costs and inadequate business model will be resolved gradually, which will promote the rapid growth of distributed photovoltaic power generation. However, affected by slower economic growth and depressing operating situation of enterprise, photovoltaic power generation projects are confronted with contract performance risks such as alteration of user and serious default of electricity charges. Therefore, corresponding investment comes to be discouraged for uncertain profits.

\section{The Impact of New Energy Development on Economic Growth}

\section{Balance on Energy Consumption Structure}

From the process of the development to the utilization, new energy has an implicit effect on regional economic growth, industrial restructuring and energy consumption structure in a short time. At the same time, it can be concluded that developing new energy will consume some energy inevitably. With the advancement of science and technology, utilization patterns and application scope are also changing continuously. There will be an imbalance between the macro-economy and the new energy through long-term accumulation, that is, tilted situation occurs. According to the characteristics mentioned above, exploitation strategies ought to vary from different regions and adapt to the local economy along with features of energy utilization. With a big gap between the eastern regions and the western of China in economy, eastern coastal areas have the more developed economic, more widely-distributed modern industrial distribution and more energy demand. Therefore, balance on energy consumption structures has received more attention in these areas. The proportion of clean energy should be improved and using high-polluting energy ought to be reduced as far as possible.

Optimizing the economic structure

Much energy and resources are invested to accelerate economic growth in the decades after the reform and opening up. The key of deepening reform is to increase the efficiency of energy and resource utilization. Adjusting and optimizing the economic structure can be achieved by reducing energy consumption to change the old mode of economic growth. In the present situation, energy consumption increases with the development of economy and society. Energy, as the basic element of social production, is of great importance to economy. With Scientific Outlook on Development advocated, exploiting new energy should also follow the concept of sustainable development. With advanced technology, efficiency enhancement and less environmental pollution would be achieved by low-carbon, efficient and eco-friendly energy, which has a far-reaching effect on industrial structure adjustment. Characterized by low-carbon economy, agriculture and service industry, new economic system, regarded new energy as its core, comes into shape, for which rationality of economic development pattern is improved at the same time.

\section{New Energy Development Strategy}

Reasonable investment in new energy

Economic growth will benefit from the appropriate development of new energy but not unreasonable investment. Therefore, corresponding regulation should be proposed to avoid the negative effects on the economy system from excessive investment or insufficient attention.

\section{Exerting Far-Reaching Effects on Economic Growth}

With much economic and social resources investment, new energy development, to some extent, will hinder economic growth in short term but exert long-term incentive effect once exploited 
successfully and maturely. Consequently, it is necessary to evaluate the investment of new energy with a long-term perspective in its development process.

\section{Deepening the Adjustment of Energy Industry Structure}

In terms of macro-economy, rising social productivity is certainly related to the increasing energy consumption of society. Due to the high cost of traditional energy, the adjustment of industrial structure ought to be accelerated to increase new energy resource utilization rate and to satisfy the social need.

\section{Development Strategy}

As the second largest economy in the world, China has the superior economic aggregate and higher energy consumption. Owing to the non-renewable traditional fossil fuels, the situation of energy shortage will be increasingly serious in long term without accelerating adjustment of industrial structure. Advantages and disadvantages, economic development status and impacts on economic growth should be taken into consideration when development strategies are formulated. Relevant departments ought to adopt a more stable development strategy.

\section{Conclusion}

With a bright prospect, the development of new energy resources can solve the problems of environmental pollution as well as energy shortage and play an important role in economic growth along with industrial restructuring. Simultaneously, official industry policies ought to be introduced correspondingly to improve the utilization efficiency and promote the healthy and sustainable economic growth of China.

\section{Reference}

[1] Papadopoulos M, Papathanassiou S, Tertzerakis S. Investigation of the flicker emission by grid connected wind turbines. Proceeding of international conference on harmonics and quality of power system, Athens, 1998, 1152 1157.

[2] J.P. Nelson, P.K. Sen, "High-resistance grounding of low-voltage systems: a standard for the petroleum and chemical industry", IEEE Trans. On Industry Applications, vol. 35, no. 4, July/August 1999, pp. 941-948.

[3] IEEE Industry Applications Society/Power Engineering Society, "IEEE Recommended practices and requirements for harmonic control in electrical power systems", IEEE Standard 519-1992.

[4] A. Bhowmik, A. Maitra, S.M. Halpin, J.E. Schatz, "Determination of allowable penetration levels of distributed generation resources based harmonic limit considerations", IEEE Trans. On Power Delivery, vol. 18, no. 2, April 2003, pp. 619-624.

[5] J.H.R.Enslin, P.J.M. Heskes, "Harmonic interaction between a large number of distributed power inverters and the distribution network", IEEE Trans. On Power Electronics, vol. 19, no. 6, November 2004.

[6] Connection guidelines: adequate requirements for the prevention of unintentional islanding", Progress in Photovoltaics: Research and Applications, vol. 11, 2003,pp. 407-424.

[7] Klessmann C, Held A, Rathmann M, et al. Status and perspectives of renewable energy policy and deployment in the European Union-What is needed to reach the 2020 targets?[J]. Energy policy, 2011, 39(12): 7637-7657.

[8] Kitzing L, Mitchell C, Morthorst P E. Renewable energy policies in Europe:Converging or diverging[J]. Energy Policy, 2012, 51: 192-201.

[9] European Photovoltaic Industry Association.Global market outlook for photovoltaics until 2014[. Brussels, Belgium: European Photovoltaic Industry Association(EPIA ), 2010.

[10] Toshihiko Noguchi, Shigenori Togashi, and Ryo Nakamoto. Short-Current Pulse-Based aximum Power Point Tracking Method for Multiple Photovoltaic and Converter Module System[J]. IEEE Transactions on Industrial Electronics, 2012, 49 (1) : 21 223. 